\title{
SHAPE OPTIMIZATION OF GLASS FAÇADE SINGLE-ARMED SPIDER SUPPORT USING FINITE ELEMENT METHOD BASED SOFTWARE
}

\begin{abstract}
In this paper the shape optimization of mechanical one-armed spider connector utilized in realization of glass facades in view of obtained Misses stress and displacement result values was discussed. Following elements in considered connector were assumed as varying: shape and dimensions of arm cross section and arm curvature direction. According to above, three different shapes of cross section were assumed: C-shape, T- shape and cross section formed from two parallel welded sheet metals on the offset from the longitudinal symmetry axis. In the performed analysis two different types of loading were investigated - maximum value of pressure and wind suction transferred via the glass element on the connector. Moreover, it was assumed that the glass plate had dimensions of $1.50 \times 1.50 \mathrm{~m}$. Whole analysis was performed with the use of finite element method based software.
\end{abstract}

Keywords: point connector, spider connector, statics, optimization, wind load

\section{Introduction}

Glass is a special kind of material utilized in many areas of life due to its mechanical and physical properties. Glass plates are formed as a result of melting silicon oxide, sodium and calcium carbonate in special furnace at high temperature around $1500^{\circ} \mathrm{C}$. Mentioned material has no crystalline structure, its amorphous. It is often called as cooled liquid, according to the fact that after the solidify process it keeps the liquid structure. Utilization of such material covers: medicine, automotive industry, civil engineering etc.

Recently in civil engineering, glass material is utilized in variety of ways. The most typical way of glass application are windows, while same material with higher load bearing capacity may be found in designs of whole facades, glazed roofs, stairs and even floors. Glass plates are frequently used by architects and engineers to underline the aesthetic appeal of newly constructed structure. Material transparency is an immense advantage, which not only allows to pass through the sun rays through the

\footnotetext{
${ }^{1}$ MSc. Eng., Częstochowa University of Technology, Faculty of Civil Engineering, Akademicka 3 street, Częstochowa, Poland, kkulinski@ bud.pcz.czest.pl

2 Assoc. Prof. Ph.D. Eng., Częstochowa University of Technology, Faculty of Civil Engineering, Akademicka 3 street, Częstochowa, Poland, jselejdak@bud.pcz.czest.pl

3 Assoc. Prof. Ph.D. Eng., Częstochowa University of Technology, Faculty of Civil Engineering, Akademicka 3 street, Częstochowa, Poland, mmajor@ bud.pcz.czest.pl
} 
structure, but also allows to obtain optically larger spaces. At this moment, it should be noted that the glass for civil engineering has been produced mainly as a transparent and as rectangular shape plates. Today's technology not only allows to obtain glass plates in any desired colour, but also any kind of shape may be produced. Rapid technological development and changes in law, which were implemented in regard to sustainable building, lead to produce glass with relatively small heat transfer coefficient. According to that, thermal comfort in the inner space is held much longer than it was in former years. Nowadays, simultaneously with the production, research concerning "smart" glass are performed. Such "smart" glass may adjust its properties to the prevailing conditions, for example in the sunny day glass plate may change its colour. However, there can be discussed many different advantages of glass, there is one main disadvantage - material is brittle. Moreover, compressive and tensile strength of considered individual glass plate is much smaller in comparison with wellknown materials such as concrete and steel.

In civil engineering glass plates may be used as decorative or load bearing elements. Dependently on place where glass plate can be utilized special requirement may be imposed. In case of glass facades, roofs and other structures exposed to the external conditions, plates should be resistant to the wind pressure/suction, UV rays, temperature fluctuations, snow load (if plate is placed horizontally) etc. In case of floors, stairs special anti-skidding coat should be provided and glass should be more resistant to attrition. It should be noted, that glass which may have a contact with human body should meet specific safety requirements. According to above three different types of glass plates are produced: singular standards glass plates, temperature/chemically tempered glass plates and laminated plates. First group which are standard singular glass plates do not meet the safety requirements. Hence these elements are used only as decorative elements and recently less and less frequently used as windows in the single family houses. Chemically/temperature tempered glass plates have higher overall strength and are much safer. In case of emergency such plates can be shattered into very small pieces. That kind of plates are commonly used in automotive industry as side windows. The last group i.e. laminated glass plates provide the highest safety level. Despite the cracks, such plate may be subjected to large deformations, whereas applied load may still be transferred onto the supports load bearing capacity in case of emergency is relatively high in comparison to the noncracked plate. Due to the utilized foil between the individual glass plates, overall strength to bending moments is much higher in regard to plates without foil. Moreover, it should be noted that the after the plate cracking, laminated coat does not pierce and glass pieces do not come off from the lamination providing extra safety. 
Sedlacek and Blank (SEDLACEK G., BLANK K. J. 1999) examined laminated plate pinned in the corners in view of obtained stress and displacement results. Authors stated that even small foil shear modulus has an important influence on obtained results of stress and deformation. Moreover, it was observed that the higher the temperature the lower the range of transferred shear stress is obtained. Crack and failure criteria for construction glass plates were discussed by Jaśkowska (JAŚKOWSKA D. 2008). Broader experimental test overview and discussion can be found in (JAŚKOWSKA D. 2009). Design details for laminated glass plates were shown by (FORNALCZYK I. 2002, BOHMANN D. 1999).

\section{Mechanical connectors/supports}

However, glass elements attract the most attention and depending on their task may be treated as important construction elements, even more important elements are glass connectors and supports. Mentioned connectors are a group of elements allowing safely transfer loads from glass plates to the supporting structure.

On the basis of scientific description provided in article (LODYGOWSKI T., et al., 2009) few different types of connectors can be indicated:

- in view of fixing scheme: joint with ball, joint with ring, rigid,

- in view of fixing shape: singular, spiders (single to four-armed), two-planes sets (joint, fixed).

In case of glass facades following point connectors are used:

- coplanar (one-sided), with head over the glass surface (two-sided) and with head between glass plates.

In the view of connection with glass plate, connectors may be divided into two other groups i.e. handle glass fixing if holes are bored in glass plate and clamp/glue fixing when glass plate is connected directly to the support. Broader connectors overview may be found in (ŁODYGOWSKI T. 2009a, SIENKIEWICZ R. 2010a, 2010b).

Utilization of specific connector depends mainly on types of loads which are transferred from glass elements, safety requirements, placing location, required aesthetic appeal etc. According to above clamped connectors are utilized in places where high rigidity or stability is required, whereas joint connectors are used to transfer transient loads for example wind. They allow small rotations on the supports which allow redistribute bending moments. In clamped supports relatively high bending moments on the supports may lead to appear visible cracks or even to element failure. From the construction point of view utilization of point connectors, which require bored holes in glass plate provides much higher safety than the clamped or glued joints. Moreover, point connectors with head over the surface of glass plate are much faster to assemble in comparison to the glued ones. It should be noted that 
plastic work of connector element should be strongly avoided, whereas deformations should be granted in a certain range - dependently on the glass plate dimensions and acting loads.

\section{Numerical models}

In this paper arm cross section shape optimization of single-armed spider connector was performed. Six different numerical models were examined in order to obtain solution with the lowest Misses stress results and vertical displacements of arm connected with the glass plate. Three different shapes of spider arm cross section were chosen for the analysis purposes i.e. parallel two sheet metals in equal $15 \mathrm{~mm}$ offset perpendicularly to the longitudinal axis of part symmetry, C-shape and T-shape arms. Moreover, for all mentioned cross sections, bend pointing upwards and downwards were investigated. Dimensions of designed single-arm spiders were shown in Fig. 1 Small icons presented in Fig. 1 indicate designed models with reverse bends. It should be noted that reverse bend in C-shape arm model have range value equal $255 \mathrm{~mm}$ (same as shown in Fig. 1a), whereas in T-shape arm model range value of reverse bend is exactly the same as shown in Fig. 1 b i.e. $350 \mathrm{~mm}$. In each T-shape and Cshape model thickness of metal parts and welds are exactly the same. In case of two sheet metals welded on the $15 \mathrm{~mm}$ offset from the longitudinal symmetry axis (see Fig. 1c), bending curvatures had same ranges as in $\mathrm{T}$ and $\mathrm{C}$-shape arm.

For the analysis purposes it was assumed that the single-armed spider supports glass plate on the edge of glazed façade. Glass plate was assumed to be square shape with dimensions of $1.50 \times 1.50$ [m]. Due to the glass plate adopted dimension and the angle equal $45^{\circ}$ between glass plate edge and vertical plane located on side of the spider arm additional torsion forces were eliminated from the connector, only pure bending was investigated.

In order to adopt values of wind pressure and suction Warsaw localization was chosen for the designed building. According to the Polish national standard PN-EN 1991-1-4, I type area of wind load and category terrain level IV was chosen. On the basis of above wind pressure with value of $690 \mathrm{~N} / \mathrm{m}^{2}$ was obtained, whereas for suction $1092 \mathrm{~N} / \mathrm{m}^{2}$, respectively. Presented values have included the safety factor equal 1.50. Analysis of each connector was made as statics with the use of finite element method based software - SolidWorks. 

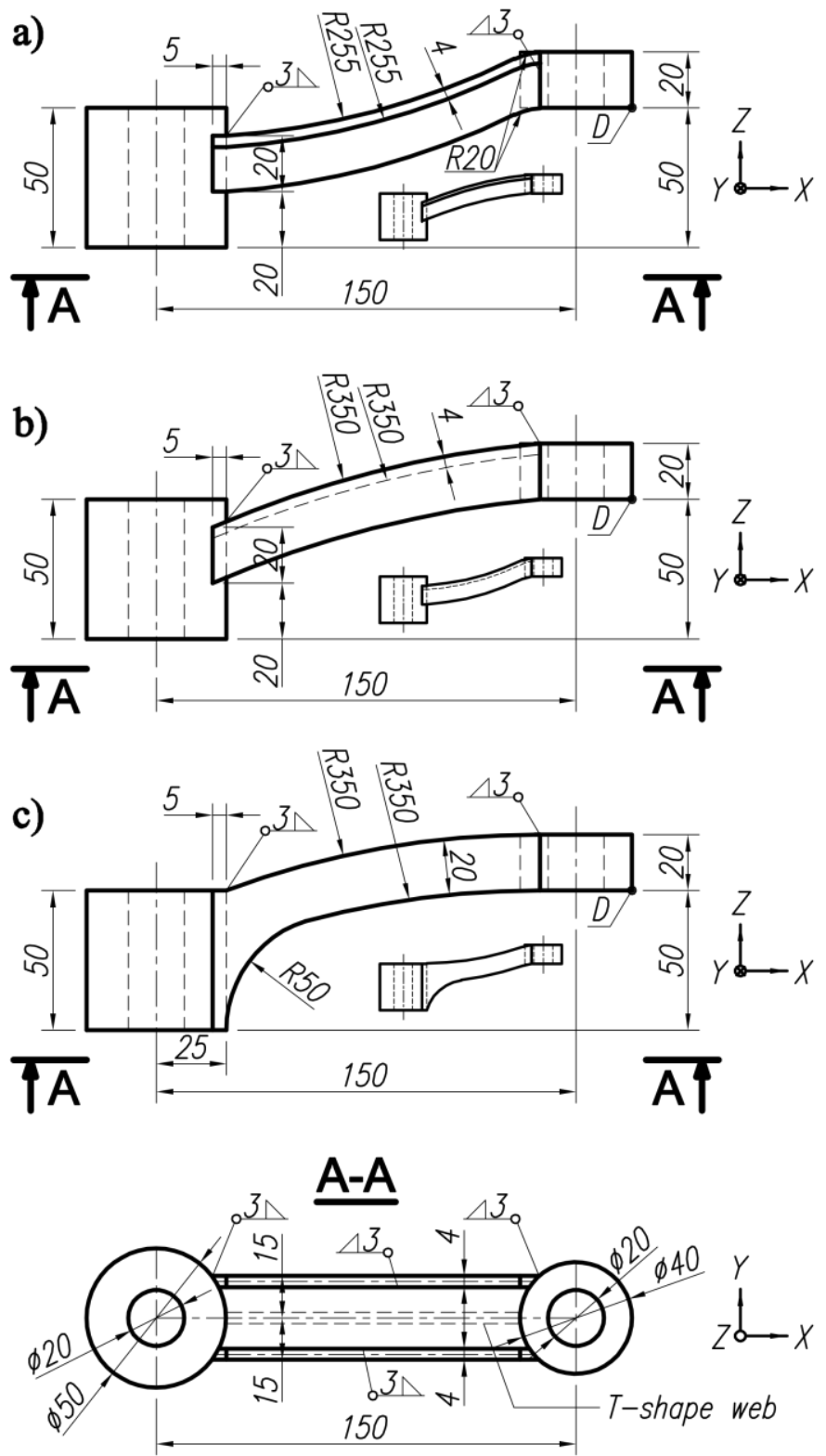

Fig. 1. Schemes of analyzed single-armed spider, a) T-shape arm cross-section with bend pointing downwards, $b$ ) $C$-shape arm cross-section with bend pointing upwards, c) arm made of two sheet metals on the offset from the part longitudinal symmetry axis. Source: own study 
In each numerical model exactly the same boundary conditions were adopted with respect to the Cartesian coordinate system presented in Fig. 1:

- Fixed Z-axis direction displacement of bottom surface of lower bushing,

- Fixed X and Y-axis displacement of bored hole inner surface,

- Contact without penetration between hex bolt and upper bushing,

- Contact without penetration between glass plate and top surface of upper bushing

- Contact without penetration between hex bolt and glass plate,

Only one quarter of glass plate was implemented in the numerical model due to symmetric boundary condition on two edges.

For the spider connector and hex bolt S235JR steel material was adopted. In SolidWorks that material was represented with elastic, isotropic material model, where Young's moduli $E=210 \mathrm{GPa}$, Poisson's ration $\mathrm{n}=0.28$ and mass was equal 7800 $\mathrm{kg} / \mathrm{m}^{3}$, respectively. For the glass plate SolidWorks glass material model was used, where Young's moduli $E=68.935 \mathrm{GPa}$, Poisson's ration $\mathrm{n}=0.23$ and mass was equal $2457 \mathrm{~kg} / \mathrm{m}^{3}$. Due to the fact that in this paper the subject of interest was single-armed spider, deformations and stress in glass plate were not discussed.

Discretization of all numerical models was performed with the use of 3D-Solid 4node tetrahedron finite elements. Mesh was based on model curvature. Single element in spider connector was assumed to be around $\sim 4 \mathrm{~mm}$, bolt was described with $\sim 2$ $\mathrm{mm}$ elements, whereas glass plate was meshed with adaptive mesh from 4 up to $15 \mathrm{~mm}$.

\section{Results and discussion}

In order to choose only one spider connector numerical model for further optimization three different values were considered: Misses stress, Z-axis displacement and mass. It should be noted that Misses stress was measured as maximum value obtained in the spider - no special location was specified. Z-axis displacement was measured for each numerical model at point "D" (see Fig. 1). Mass was measured only of spider connector - hex bolt was omitted. In Tab. 1 were presented considered values for wind pressure, whereas in Tab. 2 at wind suction, respectively. Minus sign in the $\mathrm{Z}$-axis displacement rows denotes the reverse displacement direction than for presented coordinate system in Fig. 1.

On the basis of presented results in Tab. 1 and Tab. 2 it is clearly visible that minimum values of Misses stress in both cases i.e. wind pressure and suction were obtained for the spider connector with arm made of two sheet metals bended upwards. Moreover, obtained mass in case of bend pointing upwards connector arm made of 
sheet metals was only $0.8 \%$ heavier than $\mathrm{T}$-shape, whereas for the bend pointing downwards difference was equal $1.5 \%$, respectively.

Table 1. Numerical results of single-armed connector subjected to the pressure load

\begin{tabular}{|c|c|c|c|c|c|c|c|}
\hline \multicolumn{8}{|c|}{ Wind pressure } \\
\hline \multirow{2}{*}{} & \multirow{2}{*}{ Unit } & \multicolumn{2}{|c|}{ Bend pointing upwards } & \multicolumn{2}{c|}{ Bend pointing downwards } \\
\cline { 3 - 8 } & $\begin{array}{c}\text { Sheet } \\
\text { metals }\end{array}$ & C-shape & T-shape & $\begin{array}{c}\text { Sheet } \\
\text { metals }\end{array}$ & C-shape & T-shape \\
\hline $\begin{array}{c}\text { Misses } \\
\text { stress }\end{array}$ & $\mathbf{M P a}$ & 95.2 & 96.6 & 124.2 & 91.3 & 103.1 & 160.7 \\
\hline Z-displ. & $\mathbf{m m}$ & -0.106 & -0.089 & -0.117 & -0.063 & -0.051 & -0.061 \\
\hline Mass & grams & 123.6 & 130.2 & 122.6 & 124.7 & 131.0 & 122.9 \\
\hline
\end{tabular}

Source: own study

Table 2. Numerical results of single-armed connector subjected to the suction load

\begin{tabular}{|c|c|c|c|c|c|c|c|}
\hline \multicolumn{7}{|c|}{ Wind suction } \\
\hline \multirow{2}{*}{ Unit } & \multicolumn{2}{|c|}{ Bend pointing upwards } & \multicolumn{2}{c|}{ Bend pointing downwards } \\
\cline { 3 - 8 } & $\begin{array}{c}\text { Sheet } \\
\text { metals }\end{array}$ & C-shape & T-shape & $\begin{array}{c}\text { Sheet } \\
\text { metals }\end{array}$ & C-shape & T-shape \\
\hline $\begin{array}{c}\text { Misses } \\
\text { stress }\end{array}$ & $\mathbf{M P a}$ & 103.8 & 111.7 & 192.7 & 142.0 & 154.6 & 248.6 \\
\hline Z-displ. & $\mathbf{m m}$ & 0.179 & 0.155 & 0.205 & 0.108 & 0.089 & 0.105 \\
\hline Mass & grams & 123.6 & 130.2 & 122.6 & 124.7 & 131.0 & 122.9 \\
\hline
\end{tabular}

Source: own study

For the C-shape arm cross section overall mass of connector was the highest, whereas Z-displacement of point D (see Fig. 1) was the lowest from all considered numerical models. It was connected with higher rigidity due to the utilization of web between two flanges. Analyses for all numerical models were performed with the S235JR steel class, thus the yield stress was established as $220 \mathrm{MPa}$. According to that in suction case (see Tab. 2) T-shape arm cross-section connection between upper bushing and connector arm started to work in plastic state. In order to decrease the value of Misses stress, web thickness should be increased. Indirectly Z-displacement would be decreased, however overall connector mass would increase. Moreover, in order to 
decrease the Misses stress to the same level as in sheet metals cross-section, web and flange should have at least $8 \mathrm{~mm}$, respectively. Misses stress redistribution plot for the point fixing with arm made of sheet metal bended downwards, subjected to the pressure wind load was presented in Fig 2. Displacement plot on Z-axis direction for connector with arm made of sheet metal bended upwards, subjected to the suction wind load was presented in Fig. 3.

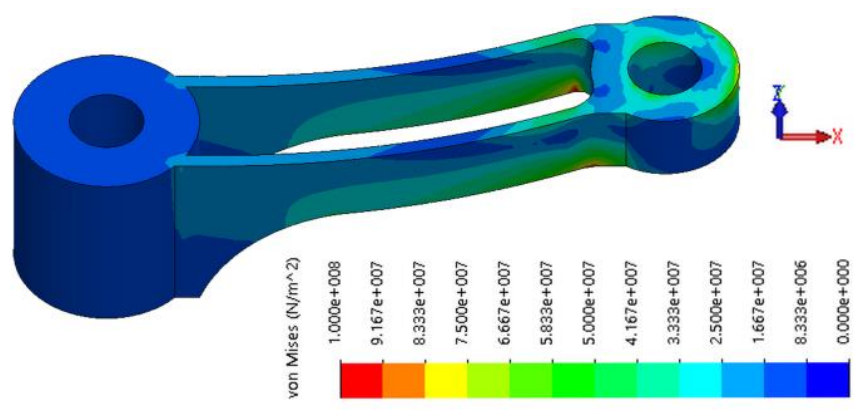

Fig. 2. Misses stress redistribution band plot for the connector with arm made of sheet metals bended downwards, subjected to the pressure wind load.

Source: own study

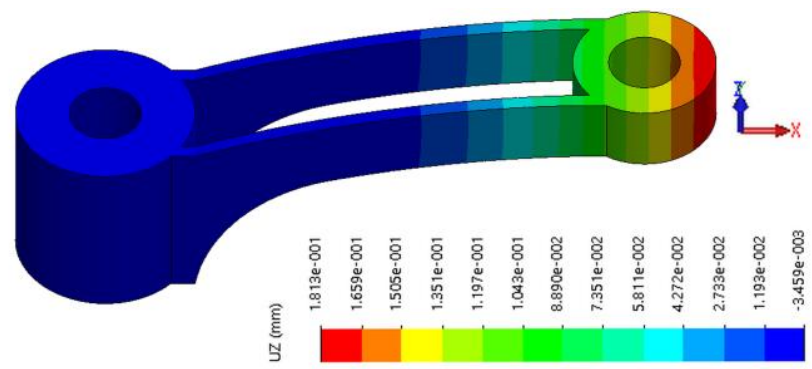

Fig. 3. Z-axis displacement band plot for the connector with arm made of sheet metals bended upwards, subjected to the suction wind load.

Source: own study

Knowing that the maximum Misses stress for the arm made of two sheet metals with bend pointing upwards was $103.8 \mathrm{MPa}$, further optimization could be performed. At first sheet metals arm thickness was decreased from 4 up to $3 \mathrm{~mm}$. Percentage Misses stress and Z-axis displacement increase and percentage mass decrease in comparison to the previous connector arm was presented in Fig. 4. 


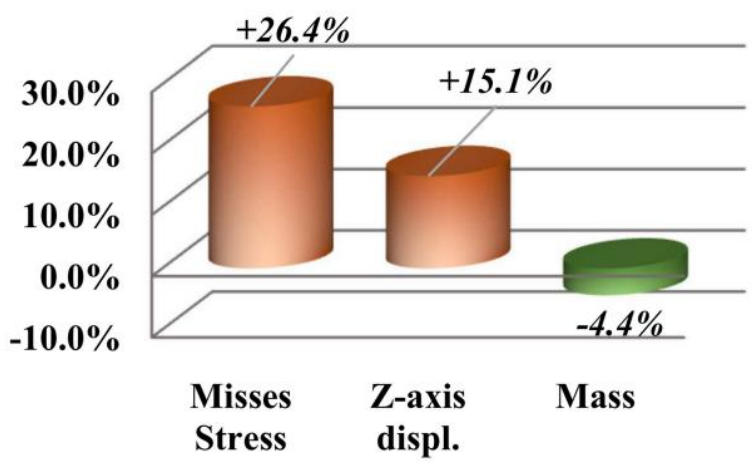

Fig. 4. Percentage Misses stress, Z-axis displacement increase and weight reduction in the optimized model.

Source: own study

According to the values presented in Fig. 4. one can state that weight was only slightly reduced to 118.1 grams, while stress increased up to $131.2 \mathrm{MPa}$, which is still far beyond the yield stress of S235JR steel class. Value of Z-axis displacement should not exceed the value of $1_{\text {eff }} / 500$ which was equal $0.34 \mathrm{~mm}$. Obtained value was equal $0.206 \mathrm{~mm}$ which may be treated as acceptable. At this point it is worth to realize that reducing weight through decreasing thickness of arm cross-section leads to less rigid spider. In any case, where glass plate would have rectangular shape, additional torsion forces should have been considered. Utilization of discussed optimized spider with rectangular glass plates could result in connector failure. Hence, in above mentioned cases C-shape arm cross-section should be considered, which have higher torsion resistance.

\section{Conclusion}

In this paper optimization of cross section shape in single-armed connector was performed. According to assumed square shape glass plate, arm made of two sheet metals on the offset from the longitudinal symmetry axis was chosen. Furtherly, weight of adopted connector was reduced, via the decreased thickness of sheet metals. Although, eccentrically acting forces were not considered in this paper, they must have been for supported objects with irregular shape. It is worth noting that FEM based software not only allow analyse statics problems, but also dynamics e.g. (MAJOR M. et al. 2009a), heat transfer etc. Approximate solutions of almost all areas of life problems may be solved with the use of FEM based software. 


\section{Bibliography}

1. BOHMANN D. 1999. Ein numerisches Verfahren zur Berechnung von Verbundglasscheiben. RWTH. Aachen.

2. FORNALCZYK I. 2002. Design of glazed facades and roofings with structural glass (MSc. Thesis in Polish with J. Gierczak as major advisor), Wroclaw University of Technology. Institute of Civil Engineering.

3. JAŚKOWSKA D. 2008. Cracking and failure criterion of construction glass. "Świat Szkła" 9/2008. (in Polish)

4. Łodygowski T., Glema A., SzCZerbal B., WŁochal D. 2009. Point supports in glass constructions. "Świat Szkła" 1/2009. (in Polish).

5. Łodygowski T., Glema A., Szczerbal B., WŁochal D. 2009. Numerical analysis of glass structures with point supports - part I. "Świat Szkła” 4/2009. (in Polish)

6. Łodygowski T., Glema A., SzCZERbal B., WŁochal D. 2009. Numerical analysis of glass structures with point supports - part II. "Świat Szkła” 6/2009. (in Polish)

7. MAJOR M., KULIŃSKI K., MAJOR I. 2015. Examples of FEM utilization in Civil Engineering with the use of ADINA program. Part I. WWZPCz. Częstochowa. (in Polish)

8. SedlaceK G., BlanK K. 1999. Glas im Konstruktiven Ingenieurbaum. Ernst \& Sohn. Berlin.

9. SIENKIEWICZ R. 2010. Mechanically fixed glass. "Świat Szkła” 4/2010. (in Polish)

10. SIENKIEWICZ R. 2010. Mechanically fixed glass - part II. “Świat Szkła” 5/2010. (in Polish) 